\title{
AS IMPLICAÇÕES POLÍTICAS E PEDAGÓGICAS DO CURRÍCULO NA EDUCAÇÃO DE JOVENS E ADULTOS INTEGRADA À FORMAÇÃO PROFISSIONAL*
}

\author{
Maria CiavatTa ${ }^{* *}$ \\ SONIA MARIA RUMMERT ${ }^{* *+}$
}

O conhecimento não só amplia como multiplica os nossos desejos (...). Portanto, o bem-estar e a felicidade de todo Estado ou Reino requerem que o conhecimento dos trabalhadores fique confinado dentro dos limites de suas ocupaçôes e jamais se estenda (...) além daquilo que se relaciona com sua missão.

(Bernard Mandeville)

\begin{abstract}
RESUMO: Este artigo, derivado de nossas atividades de pesquisa, visa a apresentar elementos de reflexão que concorram para a construção de propostas curriculares voltadas, especificamente, para a educação de jovens e adultos (EJA) que rompam com os parâmetros hoje hegemônicos. Para tanto, inicialmente, abordaremos a EJA como expressão das assimetrias de poder existentes entre as classes e grupos sociais. A seguir, serão abordadas especificidades desta modalidade de ensino, com destaque para as experiências de classe que esses alunos trazem como marca e como potencialidade para o espaço educativo. Finalmente, será referida a questão do trabalho, em sua perspectiva ontológica, como eixo articulador das propostas pedagógicas voltadas para os interesses da classe trabalhadora que acorre à escola para complementar sua escolaridade básica.
\end{abstract}

Palavras-chave: Educação de jovens e adultos trabalhadores. Currículo. Trabalho e educação.

* Este trabalho foi apresentado, originalmente, na Sessão Especial dos GTs "Trabalho e Educação" e "Educação de Jovens e Adultos", na 31ª Reunião Anual da ANPEd, em outubro de 2008.

** Doutora em Ciências Humanas (Educação) e professora da Universidade Federal Fluminense (UFF) e da Universidade do Estado do Rio de Janeiro (UERJ). E-mail: mciavatta@terra.com.br

*** Doutora em Ciências Humanas (Educação) e professora da UFF e da Universidade de Lisboa. E-mail: rummert@uol.com.br

Educ. Soc., Campinas, v. 31, n. 111, p. 461-480, abr.-jun. 2010

Disponível em <http://www.cedes.unicamp.br> 
As implicações políticas e pedagógicas do currículo na educação de jovens e adultos...

POLITICAL AND PEDAGOGICAL IMPLICATIONS OF CURRICULUM FOR YOUTH AND ADULT EDUCATION INTEGRATED TO PROFESSIONAL TRAINING

ABSTRACT: A result of our research activities, this paper presents some food for thought that may help design curricular proposals specific to youth and adult education and break the current hegemonic tendencies. To do so, it first approaches youth and adult education as an expression of the power asymmetry between different social classes and groups. Next, it deals with the specificities of this education by highlighting the students' social class experience as a feature they bring to school. It finally addresses the issue of work in its ontological perspective, as the organizing axis of pedagogic proposals in the interests of the working class members who go to school to complement their basic schooling.

Key word: Youth and adult worker's education. Curriculum. Work and education.

\section{Introdução}

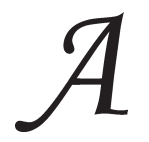

referência a Mandeville não significa incorrer no erro metodológico do anacronismo, transpondo de forma linear sua lógica para os dias atuais. Entretanto, uma análise das iniciativas educacionais destinadas, pelo Estado brasileiro, à classe trabalhadora ao longo da história evidencia, até hoje, a existência de tangenciamentos entre essa lógica e os fundamentos teórico-práticos da educação. A franqueza ou cinismo da frase é escassa em nossos dias, mas esse ideário permeia a cultura, a lógica e a prática da educação destinada aos trabalhadores. No caso específico da educação de jovens e adultos (EJA), aqui abordada como o conjunto de ações formais destinadas à elevação da escolaridade básica, podemos afirmar que essa lógica ainda a impregna e constitui uma clara expressão da dualidade estrutural fundante do modo de produção capitalista.

Ao longo do período republicano, as políticas socioeconômicas distintas em vários aspectos, mas guardando como ponto comum a marca da concentração da riqueza material e simbólica - expressaramse, no âmbito da educação, em um quadro de precariedade da oferta de ensino público à população em idade escolar, que impôs à classe trabalhadora um baixo grau de escolarização que perdurou durante quase todo o século XX. 
Nas décadas finais desse século, as correlações de forças derivadas das intensas disputas por hegemonia se expressam em várias mudanças de caráter legal. É promulgada uma nova Constituição (1988), uma nova Lei de Diretrizes e Bases da Educação (Lei n. 9.394/97) é aprovada em conturbado e controverso processo e, no âmbito da EJA, entra em vigor um conjunto de documentos que constitui hoje suas referências diretas ou indiretas. Desse conjunto, destacamos as Diretrizes Curriculares para a Educação de Jovens e Adultos, as Diretrizes Curriculares para o Ensino Fundamental e as Diretrizes Curriculares para o Ensino Médio. A esse arcabouço legal, construído nos anos de 1990 , vieram somar-se, a partir de 2003 , decretos que pautaram reformas educativas e ampliaram a implementação de programas e projetos voltados para a EJA.

No contexto do tema de que nos ocupamos agora, importa ressaltar, na primeira década do século XXI, a passagem da descrença e descaso com a educação de jovens e adultos para uma inédita oferta de programas governamentais que se propóem a associar o resgate da escolarização básica com a educação profissional. Dentre eles, destacamos o Projeto Escola de Fábrica, o Programa Nacional de Inclusão de Jovens (PROJOVEM) e o Programa Nacional de Integração da Educação Profissional com a Educação Básica na Modalidade de Educação de Jovens e Adultos (PROEJA). ${ }^{1}$ Ao nos referirmos a esse amplo conjunto de ofertas, faz-se necessário sublinhar que a diversidade de programas hoje em curso não supera as desigualdades de nosso fragmentado quadro educacional, mas, ao contrário, as acentua. Assim, a ausência de oferta, característica do século anterior, é substituída por uma ampliação expressiva de oportunidades de acesso a cursos que, embora diferenciados, guardam como ponto comum, no mais das vezes, as características que irão convergir para o que Kuenzer (2005) denominou como "certificação vazia".

A ampliação das possibilidades de acesso à certificação vazia constitui, na realidade, uma expressão do que Gramsci (2000) identificou como sendo a "marca social da escola". Essa marca (Rummert, 2006, 2007) é dada pelo fato de que cada grupo social possui um tipo de escola próprio, "destinado a perpetuar nestes estratos uma determinada função tradicional, dirigente ou instrumental" (Gramsci, 2000, p. 49). A questão das assimetrias de poder, tal como se explicitam na educação, foi objeto de rica análise empreendida por Manacorda 
As implicações políticas e pedagógicas do currículo na educação de jovens e adultos...

(1989), que demonstra como as múltiplas formas da distribuição desigual do conhecimento em favor dos dominantes marcam a história da educação.

Também E. P. Thompson - historiador inglês que se dedicou especialmente à educação de adultos - evidencia em seus escritos tanto os mecanismos de manutenção dessa assimetria de poder, quanto as aspirações e lutas dos trabalhadores em prol de sua própria educação. A lógica, norteadora dos processos de regulação da distribuição diferencial do conhecimento, é exemplificada pelo autor em Costumes em comum (1998), ao citar Mandeville, pensador do século XVIII, reconhecido como uma das fontes inspiradoras, por exemplo, de Hayek (1987), que formulou as bases do ideário neoliberal. Para Mandeville (apud Thompson, 1998, p. 15), "Quanto mais um pastor, um arador ou qualquer outro camponês souber sobre o mundo e sobre o que é alheio ao seu trabalho e emprego, menos será capaz de suportar as fadigas e as dificuldades de sua vida com alegria e contentamento". ${ }^{2}$

Encontramos, assim, em Mandeville, bem como em aspectos da cultura atual, uma expressão da marca social da escola dos subalternizados, que se assenta na cultura dos mínimos (Fernández, 2006). Esse quadro, que irá se alterar, gradativamente, pari passu, com os processos de complexificação das sociedades, num intrincado movimento de forças sociais em disputa, se explicita também no quadro educacional brasileiro, marcado, até hoje, pela ausência de efetivas políticas de universalização das condições de acesso e permanência no ensino fundamental e médio, bem como de universalização do padrão de qualidade das ofertas educativas. Nesse quadro, as políticas governamentais, no âmbito da EJA, revestem-se de um caráter de aparente democratização, marcado pela ampliação de oportunidades de elevação de escolaridade, na realidade, funcionais às atuais formas de divisão social do trabalho e aos novos requerimentos do processo produtivo na atual fase de acumulação do capital.

Encontramo-nos, portanto, diante de um quadro em que são corroboradas as análises seminais de Marx (1979, 1980), Gramsci (1978) e Kosik (1976), ao evidenciarem o fato de que todo processo produtivo, ao acarretar novas configuraçôes dos processos de trabalho e de sua divisão social, apresenta novas demandas no que concerne ao trabalhador necessário. Essa perspectiva ressalta a articulação orgânica 
entre trabalho e educação e nos permite compreender o currículo como uma forma de materialização dessa articulação. É possível, assim, transcender as interpretações hegemônicas que apresentam as relações entre trabalho e educação como resultantes lineares do plano fenomênico e o currículo como mera expressão de um processo intraescolar e/ou pedagógico, em sentido estrito.

Essa ampla e complexa problemática, brevemente esboçada nesta introdução, nos convoca a proceder a reflexões acerca da temática do currículo, visando contribuir para a superação da "marca social da escola" tal como vivenciada pelos jovens e adultos trabalhadores. Com esse objetivo, apresentaremos, a seguir, considerações acerca de especificidades da EJA, de suas potencialidades quando referenciada nas experiências da classe trabalhadora, bem como dos princípios que devem ser considerados quando nos propomos a formular propostas pedagógicas comprometidas com a emancipação humana, tal como concebida por Marx (1989). Finalmente, abordaremos a questão do trabalho, em sua perspectiva ontológica, explicitando a importância de tomá-lo como eixo articulador das propostas pedagógicas voltadas para os interesses da classe trabalhadora.

A especificidade da educação de jovens e adultos e suas implicações curriculares

Ao pensarmos na EJA, não podemos fazê-lo de forma abstrata, ignorando sua história que, tal como se configurou até hoje, é permeada por uma perspectiva negativa que a associa a algo semelhante a compensar, consertar ou curar, como destaca Fernández (op. cit.). Tal perspectiva desqualifica, a priori, os alunos jovens e adultos da classe trabalhadora que trazem para o espaço-tempo escolar tanto a marca da destituição de direitos, quanto a riqueza de suas experiências de luta pela vida.

Por um lado, como afirmou Thompson (1998, p. 43), esses adultos "que não conseguem provar a si mesmos serem suficientemente iguais para galgar os degraus da oportunidade, têm gravada sobre si mesmos (...) uma sensação não de diferença, mas de fracasso humano”. Por outro, suas trajetórias de classe lhes conferem um conhecimento da materialidade da vida que não pode ser ignorado pela escola. Para 
As implicações políticas e pedagógicas do currículo na educação de jovens e adultos...

Gramsci (2000), faz-se necessário que a escola se constitua em espaço de potencialização dos processos de aprendizagem vivenciados fora dela e impregnados de saberes socialmente construídos. Essa perspectiva impõe como desafio uma nova relação teoria-prática, formulando, em novas bases, os aspectos referentes à organização e ao funcionamento da escola, em que estão inscritas as propostas curriculares. Tal desafio vai ao encontro dos fundamentos de suas teses acerca da "escola unitária", como expõe nos Cadernos do Cárcere, em particular no Caderno 12 (2000), e do ideário da educação politécnica, tecnológica ou integrada entre a formação geral e a educação profissional, no sentido de superar o ser humano cindido, historicamente, pela divisão social do trabalho entre a ação de executar e a ação de pensar, dirigir ou planejar (Ciavatta, 2005). Nessa perspectiva, a formação humana exige da escola profundas reformulações para abrigar e potencializar a riqueza e a diversidade que para ela convergem quando recebe os alunos da classe trabalhadora.

Nossa escola organiza-se, em todos os níveis, pela lógica fordista. Como tal, está estruturada para ensinar a muitos alunos - como se eles fossem apenas um - os mesmos conteúdos fragmentados a serem apreendidos de forma previsível e igual. Construir um novo projeto educativo, expresso em um currículo transformado e transformador, que rompa com os parâmetros impostos pelas forças dominantes, é uma tarefa que se impõe quando nos voltamos para a educação de jovens e adultos, a qual não pode ignorar as experiências que esses trazem como marca e como potencialidade para o espaço educativo. Essa perspectiva é claramente explicitada por Thompson (2002, p. 13), quando afirma:

O que é diferente acerca do estudante adulto é a experiência que ele traz para a relação. A experiência modifica, às vezes de maneira sutil e às vezes mais radicalmente, todo o processo educacional; influencia os métodos de ensino, a seleção e o aperfeiçoamento dos mestres e do currículo, podendo até mesmo revelar pontos fracos ou omissóes nas disciplinas acadêmicas tradicionais e levar à elaboração de novas áreas de estudo. (Grifo nosso)

A questão da experiência pressupõe sua abordagem dialética que implica, por um lado, abandonar a visão dominante, claramente preconceituosa, que desqualifica, a priori, os saberes acumulados pela classe trabalhadora em suas múltiplas experiências de vida. Por outro lado, exige que não nos enredemos em uma visão romântica, que confere às 
experiências, também a priori, um caráter de positividade. Trata-se, portanto, de reconhecer a classe como locus de construção da vida, da experiência do trabalho e dos conhecimentos dela derivados. Para tanto, faz-se necessário ir além dos estudos-narrativas referentes aos saberes do trabalhador que, por serem encerrados em si mesmos, se afastam dos processos de construção dos sujeitos coletivos, conformando-se à lógica individualizante, e que parecem ignorar que todo o conhecimento é socialmente construído.

Mais uma vez, é necessário recorrer a Gramsci para sublinhar a importância da passagem do senso comum para a consciência filosófica, processo complexo que nos foi claramente apresentado por Saviani (1980). Trata-se, assim, de compreender a experiência numa perspectiva de prospecção, de possibilidade de reflexão crítica sobre ela própria e de ampliação de seu arco de possibilidades.

Nesse sentido, o senso comum, as visões folclóricas, o empírico imediato, a realidade complexa e diferenciada constituem o ponto a partir do qual se estruturam uma visão crítica da realidade e uma concepção de cultura que ressaltam a multiplicidade de manifestações que, mesmo aparentemente desordenadas e artificialmente apartadas umas das outras, constituem um tecido no qual estão expressas as mais diversas significações e tensóes de ordem econômica, social, política, étnica e geracional. São expressões de diferentes épocas, de modelos societários, de classes sociais e de múltiplas interações dialéticas que, permanentemente, as fazem integrarem-se, reestruturarem-se e/ou transformarem-se.

A compreensão da educação de jovens e adultos trabalhadores a partir dessa perspectiva permite enunciar, conforme Rummert (2006), alguns pressupostos orientadores da organização curricular. $\mathrm{O}$ primeiro reside em que todas as relações pedagógicas são socialmente determinadas e constituem expressões das correlações de forças que marcam uma dada sociedade. Como resultantes do fazer humano, dentro de circunstâncias históricas dadas, as formas que tais relações assumem no âmbito escolar também constituem expressão de correlações de forças, relações de hegemonia, em um dado momento histórico, num processo permanentemente marcado por tensōes e assimetrias de poder, como já referido.

Como segundo pressuposto, destacamos o fato de que as escolhas que presidem a organização curricular derivam da eleição de critérios de caráter sócio-político que, por sua vez, definem a escolha de 
As implicações políticas e pedagógicas do currículo na educação de jovens e adultos...

procedimentos teórico-metodológicos, de conteúdos e de sua forma de organização (Tragtenberg, 1981). Assim, ao contrário do que o mito da neutralidade procura fazer crer, estão implícitas intenções fortemente ancoradas em projetos políticos construídos no âmbito geral da sociedade.

$\mathrm{Na}$ elaboração do currículo, não se pode ignorar que os conhecimentos produzidos pela sociedade são privatizados, transformados em mercadorias e distribuídos de forma desigual, segundo as necessidades e os interesses dominantes. Verifica-se, assim, a permanente dualidade imposta pelo modo de produção capitalista, entre o trabalho e a ciência; essa última concebida como força produtiva, transformada em propriedade privada pelo capital.

Deve-se, assim, "possibilitar que os alunos se apropriem solidamente dos conhecimentos científicos fundamentais para analisar as manifestações da vida" (Pistrak, op. cit., p. 96). Ao valermo-nos dessa indicação, pretendemos contribuir para a superação das interpretações da realidade que explicam o mundo de modo ingênuo, caótico e/ou desordenado. Do mesmo modo, pretende-se superar as leituras de mundo individuais e individualistas.

Tal processo de superação não pode prescindir do exercício de compreensão da realidade num contexto que transcenda o plano da aparência, o que é, ao mesmo tempo, complexo e difícil, mas fundamental e necessário. Trata-se do esforço de passar, mediante a análise, do empírico/concreto, em sua representação imediata, ao concreto pensado, este sempre síntese de múltiplas mediações e determinações. Como afirma Saviani (2008), "para o aluno concreto - enquanto síntese de relações sociais - é da maior importância passar da visão de senso comum para uma visão articulada, uma visão científica, ter acesso a conteúdos elaborados".

Dessas reflexões deriva um terceiro pressuposto: a elaboração de uma proposta curricular não pode ser definida independentemente dos sujeitos envolvidos no processo, nem da dimensão histórica e política em que é elaborada. Focalizar o currículo, a partir de suas relações com o contexto sócio-político mais amplo, determina a necessidade do uso de categorias que se afastam do âmbito puramente prescritivo. As categorias cultura, trabalho, controle social, poder, hegemonia e ideologia constituem elementos fundamentais para explicitar essas relações na 
perspectiva de ruptura com as ações pedagógicas conservadoras. A elaboração do currículo exige, portanto, uma "teoria de pedagogia social", sem a qual "nossa prática levará a uma acrobacia sem finalidade social e utilizada para resolver os problemas pedagógicos na base das inspirações do momento, caso a caso, e não na base de concepções sociais bem determinadas" (Pistrak, op. cit., p. 29).

A construção dessa proposta, que também é processo formativo para todos que nela se envolvem, ancora-se no objetivo maior da formação humana plena, o que significa assegurar aos jovens e adultos trabalhadores "a compreensão das relaçôes sociais subjacentes a todos os fenômenos” (Ciavatta, 2005, p. 85). Dessa perspectiva deriva um conjunto de questôes inerentes à formulação de uma proposta curricular que se pretenda comprometida com as transformações estruturais da realidade. Dentre elas, nos limites deste trabalho, destacamos a centralidade da história e a relação entre totalidade e particularidade, como princípios epistemológicos orientadores do processo dialético de construção social do currículo.

A centralidade da história, como processo e como método (Labastida, 1983) - e não como um conteúdo a ser acrescido -, é elemento constitutivo do currículo. Trata-se de tomar, como eixo estruturante, o resgate da historicidade dos conhecimentos, bem como das formas como são apropriados no espaço-tempo escolar, explicitando seu caráter de expressão do trabalho humano. Do mesmo modo, a centralidade da história, como referente organizador do currículo, nos impóe a compreensão dos jovens e adultos trabalhadores como seres histórico-sociais. Dessa perspectiva deriva o reconhecimento de que os elementos que prevalecem na consecução do currículo constituem expressão dos processos de correlações de forças num dado momento histórico. Constituem, portanto, a expressão do real no âmbito escolar.

Como um todo histórico e articulado que se constrói por diferentes tipos de inter-relações que os homens estabelecem entre si, com a natureza e, também, com os artefatos que produzem, o real abriga, de forma integrada, um amplo espectro de elementos que expressam, dentro de suas particularidades, múltiplas dimensões das diferentes ciências. Compreender a historicidade dessas ciências, bem como seus processos de transformação, implica compreender a realidade como um complexo de relações sociais que integram uma unidade só compreensível a partir da categoria totalidade. 
As implicações políticas e pedagógicas do currículo na educação de jovens e adultos...

A totalidade, tomada aqui como princípio epistemológico, não pode ser compreendida como soma de múltiplas partes (Kosik, 1976). Enquanto categoria "saturada de concreto" (Saviani, 1980, p. 12), ela constitui um todo estruturado que evidencia, simultaneamente, tanto os nexos entre os diferentes aspectos do conhecimento, quanto as particularidades que não podem ser desconsideradas.

Compreendendo o currículo também como uma totalidade "articulada, construída e em construção” (idem, ibid.), podemos concebêlo como locus fecundo de explicitação das relações entre totalidade e particularidade inerentes a todo o conhecimento. Trata-se, portanto, de conceber o currículo como um movimento dialético em que totalidade e particularidade se completam e colocam, permanentemente, novos desafios aos processos de produção e apropriação do conhecimento.

As abordagens pluridisciplinares ou interdisciplinares não elidem as especificidades dos diferentes corpos de conhecimento. Isso não significa ignorar o fato de que as fronteiras entre as ciências são precárias, flutuantes e, porque socialmente construídas, transitórias. Por outro lado, significa, também, um alerta para que não se incorra em abordagens que, por serem pouco fundamentadas, corroborem, de formas diferenciadas, práticas que podem ser abrigadas no espectro da cultura dos mínimos, tão presente na EJA, pois, como alertou Gramsci (2000), nenhuma contingência histórica justifica as práticas de aligeiramento na educação da classe trabalhadora.

\section{O trabalho como eixo articulador do currículo de EJA}

Ao refletirmos sobre o trabalho como eixo articulador de EJA, reiteramos os pressupostos apresentados anteriormente: primeiro, todas as relações pedagógicas são socialmente determinadas e constituem relações de forças que marcam uma dada sociedade e, consequentemente, os serviços sociais oferecidos à população, entre os quais, a educação. Segundo, as escolhas que presidem a organização curricular derivam de critérios de caráter sócio-político que, por sua vez, definem os procedimentos teórico-metodológicos e as práticas educativas. Estas são ações educacionais que supõem conhecimentos, valores, atitudes e comportamentos face à realidade em que alunos, professores e gestores vivem e produzem seus meios de vida. Supóem, assim, trabalho, cultura, ciência e tecnologia, que são diferentes aspectos do mundo complexo da 
sociedade atual e que devem estar presentes na estrutura curricular. Eles são parte da totalidade social que é a vida humana no planeta.

Não apenas a educação básica (fundamental e média) tem sido negada à população brasileira, particularmente aos jovens e adultos de reduzida escolaridade formal, como também a qualidade da educação oferecida prescinde de elementos fundamentais para o domínio de técnicas e a compreensão do mundo em que vivem. Este é o âmago da discussão sobre a educação politécnica, que fez parte das lutas pela LDB nos anos de 1980, e a polêmica sobre a formação integrada nos termos da lei (Decreto n. 5.154/04, incluído na LDB, Lei n. 9.394/97, pela Lei n. 11.741/2008), que colocam a questão do trabalho como ponto fundamental para que a EJA alcance "o aluno concreto - enquanto síntese de relaçôes sociais (...)” (Saviani, 2008). Mas o que é o trabalho para o qual os jovens são preparados? Como se ensina a trabalhar? Qual é a história do trabalho que se ensina? Quais são os direitos assegurados aos trabalhadores?

A sociedade brasileira tem uma dívida secular para com a população trabalhadora, relegada, desde os primórdios do país, a não receber conhecimentos, senão aqueles que fossem necessários ao trabalho produtivo no campo e nos espaços urbanos. Mais tarde, com séculos de atraso em relação aos países europeus colonizadores, o ideário educacional necessário à produção capitalista se implantou, de modo escasso e limitado, apenas nas funçôes de ler, escrever, contar e aprender um ofício.

Celso Suckow da Fonseca (1986) relata em detalhes os primórdios da formação profissional no Brasil e a educação plena negada pelos políticos e por intelectuais comprometidos com o modelo latifundiário e, depois, industrial e agroindustrial, que atuaram na vida política do país e na organização dos sistemas de ensino. Manteve-se sempre, por artifícios legais e administrativos, a meia-educação para a população. $\mathrm{O}$ autor lamenta que, longamente, seguiu-se a "velha filosofia" que relegava as atividades manuais, os ofícios, aos mais pobres:

A solução aristocrática que o Império deu ao problema da instrução, procurando formar uma elite altamente culta, composta dos elementos economicamente mais elevados, em contraste com a massa quase analfabeta dos possuidores de menores recursos, só serviria para firmar mais fundamente no espírito do povo a ideia do desprezo pelo trabalho executado 
As implicações políticas e pedagógicas do currículo na educação de jovens e adultos...

com as mãos e, consequentemente, do ensino que a ele fosse destinado. (1986, p. 187-188)

Predominava o pensamento tradicional europeu, "a velha filosofia” que alimentou os privilégios da aristocracia antes da Revolução Francesa de 1789 e foi apropriada pela Revolução Industrial, por meio da superexploração do trabalho (jornadas prolongadas até a exaustão, ambientes insalubres, trabalho de crianças e mulheres). A ordem econômica se completava nas restrições à instrução, aos conhecimentos.

Mas não se manteve apenas a meia-educação. Além das condições de vida e de trabalho empobrecedoras, pela insuficiência de bens e serviços para os trabalhadores e suas famílias, cultivou-se a escola somente até a $4^{a}$ série. Recursos limitados não permitiram, até hoje, a educação básica (fundamental e média) universalizada, gratuita e de qualidade para toda a população; mantém-se a desvalorização da carreira de professor, a indução ao ensino técnico e profissional.

Nos Cadernos do cárcere, Gramsci (apud Coutinho, 2003) apresenta, como primeiro elemento da ciência e da arte política, o fato de que existem governantes e governados. Ao falar sobre a educação de jovens e adultos, importa a educação dos governados. A arte política é a catarse ou passagem do momento meramente econômico ao ético-político, quando se estrutura a consciência humana em sociedade. Isso implica a superação dos interesses corporativos e a elaboração de uma vontade coletiva emancipadora dos grilhões da submissão a todas as formas de opressão, entre as quais o trabalho explorado.

Conhecendo de perto o fordismo, para Finelli (2003), Gramsci compreendeu que ele é o núcleo do americanismo que racionaliza e simplifica os processos de trabalho, através da eliminação de tempos e movimentos supérfluos, e também racionaliza e simplifica os vários âmbitos da vida social. Dessa maneira, gera-se "um novo tipo humano, adequado ao tipo de trabalho e de processo produtivo" (Gramsci, apud Finelli, op. cit., p. 100) e uma determinada consciência social adaptada às necessidades do capital.

Somente a partir de uma concepção de sociedade organizada em classes sociais, a partir da divisão técnica e social do trabalho e das contradições que ela engendra, é possível entender a aparente indefinição que se projeta sobre a estrutura curricular quantos aos conhecimentos sobre o trabalho (Ciavatta, 2008). 
Na prática, a separação entre as técnicas e seus fundamentos contrariou a lei máxima da educação e reafirmou a dualidade educacional entre trabalho manual e trabalho intelectual, característica histórica da sociedade brasileira e aspecto marcante das sociedades modernas com base na divisão técnica e social do trabalho. A ênfase no aumento da produtividade e na competitividade das empresas justificou a implantação do Decreto n. 2208/97 e muitas das dificuldades de reorganizar as práticas educativas, com base na sua revogação e na alternativa da formação integrada aberta pelo Decreto n. 5.154/04 para o ensino médio regular e a educação de jovens e adultos:

Remetemos o termo ao seu sentido de completude, de compreensão das partes no seu todo ou da unidade no diverso, de tratar a educação como uma totalidade social, isto é, nas múltiplas mediações históricas que concretizam os processos educativos. No caso da formação integrada ou do ensino médio integrado ao ensino técnico, queremos que a educação geral se torne parte inseparável da educação profissional em todos os campos onde se dá a preparação para o trabalho: seja nos processos produtivos, seja nos processos educativos como a formação inicial, como o ensino técnico, tecnológico ou superior. (Ciavatta, 2005, p. 84)

Mesmo como uma lei elaborada no contexto da reestruturação produtiva e das políticas neoliberais, não foi a LDB que levou à separação entre a formação geral e a educação profissional. $\mathrm{O}$ artigo $2^{\circ} \mathrm{da}$ Lei n. 9.344/96 diz que "a educação (...) tem por finalidade o pleno desenvolvimento do educando, seu preparo para o exercício da cidadania e sua qualificação para o trabalho"; e o artigo 22 fala que a educação "(...) deve fornecer-lhe os meios para progredir no trabalho e em estudos posteriores".

A formação integrada exige que se trate o trabalho como princípio educativo. Para tanto, precisamos da análise marxiana do trabalho como valor de uso e como valor de troca. Como valor de uso, o trabalho é atividade fundante da produção da existência, ontocriativa (Lukács, 1978 e 2004). Como valor de troca, o trabalho se apresenta nas suas formas históricas, de trabalho assalariado, alienado, no sentido de que o trabalhador é expropriado do tempo de trabalho apropriado pelo dono do capital e não se reconhece no produto do trabalho, no conhecimento e na sociabilidade gerados pelo trabalho coletivo (Marx, 1980). 
As implicações políticas e pedagógicas do currículo na educação de jovens e adultos...

Contraditoriamente, vive-se em um mundo relacionado por múltiplos meios de comunicação, pela globalização das mercadorias e das ideologias, pela mundialização financeira e cultural do capital (Chesnais, 1996 e 2003), e prescreve-se uma educação profissional reduzida às funções operacionais, comportamentos e competências exigidas pelas empresas, tanto para o ensino médio como para a EJA. A essa visão funcional da educação, opomos uma visão ampliada do mundo do trabalho.

Saviani (2007, p. 158) destaca, na história da humanidade, o vínculo estreito entre o sistema de aprendizado e o trabalho. Contudo, com a nova determinação do modo de produção capitalista, "os ingredientes intelectuais, antes indissociáveis do trabalho manual”, irão se incorporar às máquinas, surgindo daí a separação entre o trabalho manual e o intelectual.

Dependendo das condições de trabalho, dos fins a que se destina e da apropriação do produto e dos processos que lhe são inerentes, o trabalho não é fonte de bem-estar, nem de formação humana, mas de sofrimento e privação, e tem um sentido pedagógico para o capital do ponto de vista de formar para a submissão às necessidades da acumulação. Quando nos referimos ao trabalho como princípio educativo, significa que buscamos superar a dicotomia trabalho manual/trabalho intelectual, incorporar a dimensão intelectual ao trabalho produtivo e formar jovens e adultos trabalhadores capazes de atuar como dirigentes e cidadãos, não apenas como governados (Gramsci, 1981).

Do ponto de vista político-pedagógico, tanto a conceituação do trabalho como princípio educativo, quanto a defesa da educação politécnica, formulada por educadores brasileiros, pesquisadores da temática sobre trabalho e educação, têm por base duas fontes fundamentais teórico-conceituais. Em um primeiro momento, a vertente gramsciana (Gramsci, 1981; Manacorda, 1975; Nosella, 1992): Gramsci propóe a escola unitária que se expressaria na unidade entre instrução (educação) e trabalho, na formação de homens capazes de produzir, mas também de ser dirigentes, governantes. Para isso, era necessário o conhecimento tanto das leis da natureza, como das humanidades e da ordem legal que regula a vida em sociedade (Gramsci, op. cit.).

Em um segundo momento, a reflexão toma forma tendo por base Lukács (1978). Em sua reflexão sobre a ontologia do ser social, como 
vimos anteriormente, o autor examina o trabalho como atividade fundamental do ser humano, ontocriativa, que produz os meios de existência na relação do homem com a natureza, a cultura e o aperfeiçoamento de si mesmo. De outra parte, o trabalho humano assume formas históricas, muitas das quais degradantes, penalizantes, nas diferentes culturas, na estrutura capitalista e em suas diversas conjunturas. Desse conjunto de ideias e debates foi possível concluir que o trabalho não é necessariamente educativo, que depende das condiçóes de sua realização, dos fins a que se destina, de quem se apropria do produto do trabalho e do conhecimento que se gera (Ciavatta, 2009).

Alguns outros aspectos merecem ser destacados por sua importância para a estrutura curricular (Ramos, 2007; Ciavatta, 2008). Primeiro, todos os conhecimentos têm por base fenômenos reais e são suscitados pelo esforço humano de encontrar solução para problemas reais. Segundo, os conhecimentos gerados e os produtos deles decorrentes trazem a marca do trabalho dos indivíduos que os produziram, mas levam, também, a um pertencimento ao gênero humano, na sua caminhada histórica que nos conduziu a altos níveis científico-tecnológicos e que ameaça nos destruir.

\section{Considerações finais}

Este texto é parte das atuais atividades de pesquisa das autoras. A complexidade do tema em torno das implicações políticas e pedagógicas do currículo da EJA exigiu que nos orientássemos por algumas questôes gerais, cuja reflexão possa contribuir para a superação da "marca social da escola" que rege as ofertas educativas para os jovens e adultos trabalhadores. Não devemos, porém, ignorar o acervo de experiências reconhecidas como inovadoras, que muito têm a contribuir para o avanço político-pedagógico dessa modalidade de ensino. Infelizmente, o limite de espaço não nos permite abordá-las aqui. ${ }^{3}$

A história da educação registra, de modo particular no sistema capitalista, a luta permanente dos trabalhadores pelo acesso aos benefícios gerados pelo trabalho, tanto no que concerne aos bens materiais quanto ao conhecimento. No mundo atual, o currículo escolar é uma peça importante para a participação de jovens e adultos nesse universo valorizado da ciência, da tecnologia e da cultura. O trabalho é a mediação fundamental do processo que se desdobra na contradição entre capital 
As implicações políticas e pedagógicas do currículo na educação de jovens e adultos...

e trabalho, na divisão técnica e social do trabalho, na formação das classes sociais e em suas lutas pela superação das desigualdades.

Também são expressivos os registros sobre como as múltiplas formas da distribuição desigual do conhecimento em favor dos dominantes marcam a história dos povos, desde a antiguidade. Por outro lado, a análise da história da escola e das teorias curriculares evidencia o fato de que a concretização das teorias pedagógicas - de caráter conservador ou transformador - no espaço-tempo escolar constitui processo marcado por um extenso elenco de dificuldades. Estas derivam de um complexo conjunto de fatores de ordem cultural, política e econômica que constituem, sob diferentes matizes, expressões do permanente processo de construção e manutenção da hegemonia.

Não pretendemos, ao longo deste trabalho, apresentar qualquer tipo de recomendação ou indicação de caráter prescritivo. Tal decisão deriva do fato de entendermos que a dimensão teórico-prática do trabalho, como organizadora dos projetos pedagógicos, não pode ser imposta ou decorrer de qualquer recomendação exógena.

O currículo constitui uma elaboração complexa que incorpora as mais diversas dimensões das relações sociais subjacentes aos processos produtivos, à cultura, ao conhecimento e à organização do espaçotempo da escola. Estas, por sua vez, expressam e incorporam valores e comportamentos cultivados e destinados politicamente aos sujeitos da educação. Assim sendo, sua compreensão só se efetiva na práxis, que não se coaduna com o trabalho prescrito.

A compreensão de todo esse processo supõe o exame de sua historicidade, na dupla dimensão da história como processo de produção social da existência; e da história como método na elucidação do real e síntese de múltiplas determinações. Trata-se, portanto, de construir uma proposta de formação integrada entre os princípios gerais e as ações específicas de educação profissional, tendo como eixo a ciência, a cultura e, portanto, o trabalho.

Recebido em maio de 2009 e aprovado em outubro de 2009.

\section{Notas}

1. O Projeto Escola de Fábrica (Lei n. 11.180 de 23/09/2005 - agora incorporado ao projovem) -, o Programa Nacional de Inclusão de Jovens (Projovem) - reestruturado 
a partir do Decreto n. 6.629 de 04/11/2008 - e o Programa Nacional de Integração da Educação Profissional com a Educação Básica na Modalidade de Educação de Jovens e Adultos (PROEJA).

2. Fábula das Abelhas, 1723 (apud Thompson, 1998, p. 15).

3. Podemos citar (i) o Projeto de Educação de Trabalhadores (PET), em que experiências de vida eram parte de um processo coletivo de produção do conhecimento e a dinâmica da ação pedagógica estruturava-se a partir da noção de trabalho e cultura como fenômenos indissociáveis (Aguiar, 2006); (ii) o Programa Integração (PI), que oferece significativas contribuiçôes teórico-metodológicas à educação de jovens e adultos trabalhadores, ao romper com a lógica do ordenamento disciplinar (Bárbara, Myashiro \& Oliveira, 2004), e (iii) o Percursos de Formação Integrada, projeto desenvolvido em escolas da rede pública, no norte da Itália, que busca facilitar a integração dos filhos dos imigrantes e adultos trabalhadores, a partir do trabalho conjunto entre as disciplinas de formação geral e formação profissional, teoria e prática do trabalho em laboratórios e oficinas (Ciavatta, 2007).

\section{Referências}

AGUIAR, L. O projeto de educação dos trabalhadores - PET - e a construção de uma prática educativa em EJA a partir do movimento sindical. 2006. Dissertação (Mestrado em Educação) - Programa de Pós-Graduação em Educação, Universidade Federal Fluminense, Rio de Janeiro.

BÁRBARA, M.; MYASHIRO, R.; GARCIA, R. Experiências de educação integral da CUT: práticas em construção. Rio de Janeiro: DP\&A, 2004 .

CHESNAIS, F. A mundialização do capital. São Paulo: Xamã, 1996.

CHESNAIS, F. et al. Uma nova fase do capitalismo? São Paulo: Xamã, 2003.

CIAVATTTA, M. A formação integrada: a escola e o trabalho como lugares de memória e de identidade. In: FrigotTo, G.; CiavatTA, M.; Ramos, M. (Org.). Ensino Médio Integrado: concepção e contradições. São Paulo: Cortez, 2005. p. 21-56.

CIAVATTA, M. Formação integrada: entre a cultura da escola e a cultura do trabalho. In: CiavatTA, M. Memória e temporalidades do trabatho e da educação. Rio de Janeiro: Lamparina; FAPERJ, 2007. p. 131-152.

CIAVATTA, M. Implicaçoes curriculares frente ao contexto politico e legal do ensino médio: questōes atuais. Texto preparado para o Seminário "O

Educ. Soc., Campinas, v. 31, n. 111, p. 461-480, abr.-jun. 2010

Disponível em <http://www.cedes.unicamp.br> 
As implicações políticas e pedagógicas do currículo na educação de jovens e adultos...

currículo de educação básica em questão”. SEE-PR, Curitiba, 10 out. 2008. (mimeo.).

CIAVATTA, M. Mediações históricas de trabalho e educação: gênese e disputas na formação dos trabalhadores (Rio de Janeiro, 1930-60). Rio de Janeiro: Lamparina; CNPq; FAPERJ, 2009.

COUTINHO, C.N. O conceito de política nos Cadernos do cárcere. In: Coutinho, C.N.; Teixeira, A.P. Ler Gramsci, entender a realidade. Rio de Janeiro: Civilização Brasileira, 2003. p. 67-82.

FERNÁNDEZ, F.S. As raízes históricas dos modelos actuais de educação de pessoas adultas. Lisboa: Educa; Unidade de I\&D de Ciências da Educação, 2006. 88p.

FINELLI, R. O "pós-moderno": a verdade do "moderno". In: Coutinho, C.N.; TeIXeIRA, A.P. Ler Gramsci, entender a realidade. Rio de Janeiro: Civilização Brasileira, 2003. p. 99-112.

FONSECA, C.S. História do ensino industrial no Brasil. Rio de Janeiro: SENAI/DN, 1986. v. 3.

GRAMSCI, A. Obras escolhidas. São Paulo: Martins Fontes, 1978.

GRAMSCI, A. La alternativa pedagógica. Barcelona: Fontamara, 1981.

GRAMSCI, A. Cadernos do cárcere. Rio de Janeiro: Civilização Brasileira, 2000. v. 2.

HAYEK, F. O caminho da servidão. Rio de Janeiro: Instituto Liberal, 1987.

KOSIK, K. A dialética do concreto. Rio de Janeiro: Paz \& Terra, 1976.

KUENZER, A. Exclusão includente e inclusão excludente: a nova forma de dualidade estrutural que objetiva as novas relaçôes entre educação e trabalho. In: Lombardi, J.; Saviani, D.; Sanfelice, J. (Org.). Capitalismo, trabalho e educação. 3. ed. São Paulo: Autores Associados; HISTEDBR, 2005. p. 77-96.

LABASTIDA, J. O objeto da história. Nova Escrita/Ensaio, São Paulo, v. 5, n. $11 / 12$, p. 161-175, 1983. 
LUEDEMANN, C.S. Anton Makarenko: vida e obra - a pedagogia na revolução. São Paulo: Expressão Popular, 2002.

LUKÁCS, G. As bases ontológicas do pensamento e da atividade do homem. Temas de Ciências Humanas, São Paulo, n. 4, p. 1-18, 1978.

LUKÁCS, G. Ontología del ser social: el trabajo. Buenos Aires: Herramienta, 2004.

MANACORDA, M.A. Marx e a pedagogia moderna. Lisboa: Iniciativas Editoriais, 1975.

MANACORDA, M.A. História da educação: da antiguidade aos nossos dias. São Paulo: Cortez; Campinas: Autores Associados, 1989.

MARX, K.; ENGELS, F. A ideologia alemã (Feuerbach). São Paulo: Ciências Humanas, 1979.

MARX, K. O capital. (Crítica da Economia Política). Rio de Janeiro: Civilizaçãao Brasileira, 1980. 2 v.

MARX, K. A questão judaica. In: MARX, K. Manuscritos econômicofilosóficos. Lisboa: Edições 70, 1989.

NOSELLA, P. A escola de Gramsci. Porto Alegre: Artes Médicas Sul, 1992.

PISTRAK. Fundamentos da escola do trabalho. São Paulo: Brasiliense, 1981.

RAMOS, M. Concepção do ensino médio integrado à formação profissional. Seminário sobre Ensino Médio, Natal, SEE-RN, 2007.

RODRIGUES, J. Ainda a educação politécnica: o novo decreto da educação profissional e a permanência da dualidade estrutural. Trabalho, Educação e Saúde, Rio de Janeiro, v. 3, n. 2, p. 259-282, set. 2005.

RUMMERT, S.M. Contribuições ao documento Bases para Proposta Político-Pedagógica de Curso a Distância de Formação Docente de Profissionais da Área da Saúde - Nível Especialização. Rio de Janeiro: Escola Nacional de Saúde Pública (FIOcruZ), 2006. (mimeo.).

RUMMERT, S.M. Gramsci, trabalho e educação: jovens e adultos pouco escolarizados no Brasil actual. Lisboa: Educa; Unidade de I\&D em Ciências da Educação, 2007. 
As implicações políticas e pedagógicas do currículo na educação de jovens e adultos...

RUMMERT, S.M. Educação de jovens e adultos no Brasil atual: do simulacro à emancipação. Perspectiva, Florianópolis, v. 26, n. 1, p.175-208, jan./jun. 2008.

SAVIANI, D. Educação: do senso comum à consciência filosófica. São Paulo: Cortez; Campinas: Autores Associados, 1980.

SAVIANI, D. Trabalho e educação: fundamentos ontológicos e históricos. Revista Brasileira de Educação, Rio de Janeiro, v. 12, n. 34, p. 152-165, jan./abr. 2007.

SAVIANI, D. Entrevista. Dossiê "Deixem os professores ensinar". RUBRA, Viseu, n. 3, out. 2008. Disponível em: <http://escolapublica2. blogspot.com/2008/10/revista-rubra-balano-crtico-do-estado.html>. Acesso em: nov. 2008.

THOMPSON, E.P. Costumes em comum: estudos sobre a cultura popular tradicional. São Paulo: Cia das Letras, 1998.

THOMPSON, E.P. Educação e experiência. In: Thompson, E.P. Os românticos: a Inglaterra na era revolucionária. Rio de Janeiro: Civilização Brasileira, 2002. p. 11-47.

TRAGTEMBERG, M. Pistrak: uma pedagogia socialista (prefácio). In: Pistrak, M.M. Fundamentos da escola do trabalho. São Paulo: Brasiliense, 1981. p. 7-24. 